\title{
Salmonella from Farm to Table: Isolation, Characterization, and Antimicrobial Resistance of Salmonella from Commercial Broiler Supply Chain and Its Environment
}

\author{
M. Nasim Sohail $\mathbb{D},{ }^{1,2}$ D. Rathnamma ${ }^{D},{ }^{2}$ S. Chandra Priya $\mathbb{D},{ }^{2}$ S. Isloor $\left(\mathbb{D},{ }^{2}\right.$ \\ H. D. Naryanaswamy $\mathbb{D}^{3}{ }^{3}$ S. Wilfred Ruban $\mathbb{D},{ }^{4}$ and B. M. Veeregowda $\mathbb{D}^{2}$ \\ ${ }^{1}$ Department of Para-Clinic, Faculty of Veterinary Sciences, Afghanistan National Agricultural Sciences and Technology \\ University (ANASTU), Kandahar-0093, Afghanistan \\ ${ }^{2}$-Department of Veterinary Microbiology, Veterinary College, Hebbal, 560024, Bengaluru, India \\ ${ }^{3}$-Karnataka Veterinary Animal and Fisheries Sciences University, Nandinagar, 585401, Bidar, India \\ ${ }^{4}$ Department of Livestock Products and Technology, Veterinary College, Hebbal, Bengaluru 560024, India
}

Correspondence should be addressed to M. Nasim Sohail; nasimnasar25@yahoo.com

Received 13 July 2021; Accepted 22 September 2021; Published 6 October 2021

Academic Editor: Stefania Cantore

Copyright (c) 2021 M. Nasim Sohail et al. This is an open access article distributed under the Creative Commons Attribution License, which permits unrestricted use, distribution, and reproduction in any medium, provided the original work is properly cited.

\begin{abstract}
Antimicrobial resistance (AMR) in poultry production chain is one of the major food safety concerns due to indiscriminate usage of antibiotics and the presence of pathogens such as Salmonella which causes infections in various stages of production. In the present study, 182 samples were collected from commercial broiler supply chain, viz., three hatcheries $(n=29)$, three commercial broiler farms (CBF; $n=99$ ), and three retail meat shops (RMS; $n=54$ ), and used for isolation and identification of Salmonella using three different selective agar media and a selective enrichment medium followed by PCR confirmation targeting the hilA gene. The overall prevalence of Salmonella was $47 / 182(25.82 \%)$, and a significantly higher $(P<0.05)$ prevalence was observed in retail meat shops (46.29\%), CBF (19.19\%), and hatcheries (10.34\%). Comparison of three agar media for isolation of Salmonella revealed that all the media were equally selective. However, PCR amplification of hilA gene fragment was significantly higher $(P<0.01)$ in selective enrichment culture tetrathionate brilliant green bile broth (TTB) as compared to all solid (agar-based) media. Susceptibility pattern against most frequently used antibiotics revealed that $100 \%$ of the isolates were resistant to at least one antibiotic. High resistance was observed for doxycycline (94.34\%), followed by cefpodoxime $(84.91 \%)$, ciprofloxacin $(72.64 \%)$, gentamicin $(65.09 \%)$, enrofloxacin $(61.32 \%)$, colistin sulphate (40.42\%), amikacin (34.91\%), ampicillin (33.96\%), neomycin (33.02), cefotaxime (30.19\%), ceftazidime (29.25\%), trimethoprimsulfamethoxazole $(23.58 \%)$, amoxicillin+clavulanic acid $(21.70 \%)$, and chloramphenicol $(12.26 \%)$; $16.98 \%$ of the isolates were ex-tended spectrum $\beta$-lactamase (ESBL) producers, and $76.41 \%$ were multidrug resistant (MDR). MDR Salmonella were significantly higher $(P<0.01)$ in RMS $(91.66 \%)$ followed by CBF $(82.75 \%)$, whereas no MDR isolates were present in the isolates from hatcheries. The results indicated a higher prevalence of Salmonella and AMR for commonly used antibiotics in the complete broiler supply chain, especially RMS and CBF. Also, this study idicated that TTB enrichment followed by PCR and colony PCR was found to be rapid, specific and time-saving method.
\end{abstract}

\section{Introduction}

Worldwide, broiler production is an intensive system which comprises of several entities, including the breeding sector, the hatcheries, and the production sector. Any of these stages of production could serve as the source for pathogenic microorganisms. Among the various pathogens, Salmonella is recognized as one of the most important zoonotic and foodborne pathogens in broiler production chain [1]. Human outbreaks of foodborne illness caused by Salmonella 
worldwide have implicated that contaminated poultry and its products as the major source [2]. Contamination of poultry and its products by Salmonella may occur at any stage of broiler production chain $[3,4]$, and hence, delineating the potential risk of Salmonella at these various stages is imperative from the perspective of consumers and public health.

In addition to causing foodborne illness, Salmonella from broiler production chain have been found to be resistant to antibiotics [5] [6], and this is a growing concern requiring attention for mitigating antimicrobial resistance (AMR). Indiscriminate use of antimicrobials in poultry flocks especially for disease prevention, treatment, and growth promotion is considered as the main reason for development of AMR in bacteria that represent a risk to human health [7]. Even though it has been documented that poultry and its products are the major source of Salmonella causing illness in humans, their role in the transmission of AMR pathogens and antibiotic resistance genes (ARGs) into the food chain is only gaining prominence.

Control of Salmonella in integrated poultry supply chain is very complicated, as it involves investigation of all the inputs as well as environmental samples. Therefore, this study was designed to investigate the prevalence and distribution of Salmonella in complete commercial broiler supply chain (hatchery, commercial broiler farm, and retail meat shops) and to determine the AMR pattern of these isolates from commercial broiler supply chain in Karnataka, India. One of the major obstacles in detection of Salmonella is the isolation, and hence, the success rate is mainly dependent on the sampling procedure combined with use of selective and sensitive culture method [8]. The conventional or standard methods for isolation of Salmonella generally take 4-7 days and are therefore laborious, require substantial manpower, and are of low in sensitivity. Several studies have reported varying levels of Salmonella recovery using different selective media following enrichment [9]. In this study, we compared Xylose Lysine Deoxycholate (XLD) agar, Xylose Lysine Tergitol 4 (XLT4), and Brilliant Green Agar with Phosphates (BGA) for isolation of Salmonella. Presumptive colonies as per colony morphology were then subjected to colony PCR targeting the hilA (hyperinvasive locus A) gene.

\section{Materials and Methods}

2.1. Location of the Study. The study location was in and around Bengaluru, India. Samples were collected from three hatcheries (Dibbur, Nelamanglla, and Doddaballapura Taluks, of Bengaluru Rural district), three commercial broiler farms (Malur, Mulbagal, and Kolar Taluks of Kolar district), and three retail meat shops (two from Ganga Nagar, Bengaluru; one from Rahmat Nagar, Bengaluru). In this study, samples were collected from birds that belonged to the same batch along the production cycle (hatchery, CBF and RMS).

2.2. Collection of Samples. The details of various samples collected from each source have been depicted in Table 1. Samples were collected at single point of time from hatcheries and retail meat shops. In $\mathrm{CBF}$, samples were collected three times in a single crop cycle, viz., day 0 , days $18-20$, and days 35-42. Samples were collected in sterile plastic containers and transported under refrigerated condition in ice packs to the laboratory and were processed on the same day.

2.3. Isolation of Salmonella. Salmonella were isolated using previously described standard methods [10]. In brief, all the samples were preenriched in Buffered Peptone Water (BPW) followed by incubation at $37^{\circ} \mathrm{C}$ for $18-24 \mathrm{hrs}$. After preenrichment, selective enrichment was done by transferring one $\mathrm{mL}$ of preenriched broth culture in to a tube containing nine $\mathrm{mL}$ of TTB and incubated at 37 to $42^{\circ} \mathrm{C}$ for 24 to $48 \mathrm{hrs}$. After selective enrichment, $1.5 \mathrm{~mL}$ of enriched TTB broth culture was subjected to DNA extraction by boiling method [11]. One $\mu \mathrm{L}$ of this DNA was used for PCR targeting the hilA gene as described previously [12]. To study the selectivity of the three commonly used agar media, one loopful of culture was streaked onto XLD, XLT4, and BGA plates. The plates were incubated at $37^{\circ} \mathrm{C}$ for $24-48 \mathrm{hrs}$ and observed for Salmonella colonies (black centred red colonies on XLD and XLT4 and reddish pink/pinkish white colonies on BGA). Four colonies per sample were selected and subjected to biochemical tests. Further, colony PCR targeting the hilA gene was performed, along with Salmonella Typhimurium $\left(\right.$ ATCC $^{\circledR} 14028^{\mathrm{TM}}$ ) as a positive control and Escherichia coli $\left(\right.$ ATCC $^{\circledR} 25922^{\mathrm{TM}}$ ) as a negative control, in addition to nuclease free water (NFW) as no template control (NTC). For colony PCR, directly each colony was just touched with the tip of sterile microtip and was mixed to a PCR mixture as a template, in a total volume of $25 \mu \mathrm{L}$. The PCR was performed with initial denaturation at $94^{\circ} \mathrm{C}$ for $5 \mathrm{~min}$ and 30 cycles of $94^{\circ} \mathrm{C}$ for $30 \mathrm{sec}, 65^{\circ} \mathrm{C}$ for $1 \mathrm{~min}, 72^{\circ} \mathrm{C}$ for $1 \mathrm{~min}$, and final extension of $72^{\circ} \mathrm{C}$ for $10 \mathrm{~min}$ using the published primers $5^{\prime} \mathrm{CGGAACGTTATTTGCGCC}$ ATGCTGAGGTAG3 ${ }^{\prime}$ and $5^{\prime}$-GCATGGATCCCCGCCG GCGAGATTGTG-3' [12].

2.4. Detection of Salmonella enterica. All Salmonella isolates obtained in the study were subjected for Salmonella enterica species specific PCR, targeting the iroB gene. As a template, one $\mu \mathrm{L}$ of DNA extracted was added to a PCR mixture, with a total volume of $25 \mu \mathrm{L}$. The PCR was performed with initial denaturation at $94^{\circ} \mathrm{C}$ for $5 \mathrm{~min}$ followed by 30 cycles of $94^{\circ} \mathrm{C}$ for $40 \mathrm{sec}$., $55^{\circ} \mathrm{C}$ for $40 \mathrm{sec}$., $72^{\circ} \mathrm{C}$ for $40 \mathrm{sec}$., and final extension of $72^{\circ} \mathrm{C}$ for $10 \mathrm{~min}$ using the published primers $5^{\prime}$ TGCGTATTCTGTTTGTCGGTCC- $3^{\prime}$ and $5^{\prime}$-TACGTT CCCACCATTCTTCCC-3' ${ }^{\prime}$ [13].

2.5. Phenotypic Characterization of AMR in Salmonella. Salmonella isolates were subjected for antimicrobial susceptibility testing based on disc diffusion assay using gentamicin $(\mathrm{GEN}=10 \mu \mathrm{g})$, amikacin $(\mathrm{AK}=30 \mu \mathrm{g})$, neomycin $(\mathrm{N}=10$ $\mu \mathrm{g})$, ciprofloxacin $(\mathrm{CIP}=5 \mu \mathrm{g})$, enrofloxacin $(\mathrm{EX}=5 \mu \mathrm{g})$, doxycycline $(\mathrm{DO}=30 \mu \mathrm{g})$, trimethoprim-sulfamethoxazole $(\mathrm{COT}=25(23.75 / 1.25 \mu \mathrm{g}))$, chloramphenicol $\quad(\mathrm{C}=30 \mu \mathrm{g})$, ampicillin $(\mathrm{AMP}=10 \mu \mathrm{g}), \quad$ amoxicillin+clavulanic acid $(\mathrm{AMC}=20 / 10 \mu \mathrm{g})$, cefotaxime $(\mathrm{CTX}=30 \mu \mathrm{g})$, ceftazidime $(\mathrm{CAZ}=30 \mu \mathrm{g})$, cefpodoxime $(\mathrm{CPD}=10 \mu \mathrm{g})$, cefotaxime + clavulanic acid $(\mathrm{CEC}=30 / 10 \mu \mathrm{g})$, ceftazidime+clavulanic acid 
TABLE 1: Samples collected from different commercial broiler supply chain.

\begin{tabular}{|c|c|c|c|}
\hline No & & Types of samples collected & $n$ \\
\hline \multicolumn{3}{|c|}{ Hatchery } & 29 \\
\hline 1 & & Swabs from egg setting room (10 swabs from different areas and pooled to one/hatchery) & 3 \\
\hline 2 & Swab & $\begin{array}{l}\text { from incubator/setter ( } 3 \text { swabs from different areas of each incubator and } 50 \% \text { of the incubator present in each hatchery } \\
\text { were sampled and pooled) }\end{array}$ & 3 \\
\hline 3 & Swal & $\begin{array}{l}\text { s from air tunnels and fans of incubators/setter ( } 3 \text { swabs from different areas of each incubator and } 50 \% \text { of the incubator } \\
\text { present in each hatchery were sampled and pooled) }\end{array}$ & 3 \\
\hline 4 & & Swabs from hatchers ( 3 swabs from different areas of each hatcher and samples were pooled) & 3 \\
\hline 5 & & Swabs from hatchers egg tray (ten trays/hatcher and one swab/tray from different areas and samples were pooled) & 3 \\
\hline 6 & & Meconium swabs (ten trays/hatcher and one swab/tray from different areas and samples were pooled) & 3 \\
\hline 7 & & Yolk sac swab of dead chicks (ten dead chicks and samples were pooled) & 3 \\
\hline 8 & & Hand swabs from hatchery workers (two swabs from two workers) & 5 \\
\hline 9 & & Boot socks from hatchery floor & 3 \\
\hline \multicolumn{3}{|c|}{ Commercial broiler farm (CBF) - three samplings—day 1 , days $18-20$, and days $35-42$} & 99 \\
\hline 1 & & $25 \mathrm{ml}$ water from water tank/shed $(25 \mathrm{ml}$ in $25 \mathrm{ml} 2 \mathrm{x} \mathrm{BPW})$ & 15 \\
\hline 2 & & $25 \mathrm{ml}$ water from 30 different nipples/shed $/(25 \mathrm{ml}$ in $25 \mathrm{ml} 2 \mathrm{x}$ BPW $)$ and pooled & 15 \\
\hline 3 & & $25 \mathrm{~g}$ feed sample from 10 different feed bags/shed and pooled & 15 \\
\hline 4 & & $25 \mathrm{~g}$ feed sample from 30 different feeders/shed and pooled & 15 \\
\hline 5 & & Faecal swabs (30 swabs/shed pooled) & 15 \\
\hline 6 & & Internal (inside the shed) environment samples using sterile boot socks/one pair/shed & 15 \\
\hline 7 & & External (outside the shed) environment samples using sterile boot socks/farm & 9 \\
\hline \multicolumn{3}{|c|}{ Retail meat shops (RMS) } & 54 \\
\hline 1 & & Swabs from surface of cutting/chopping board $\left(100 \mathrm{~cm}^{2}\right)$. Swabs were immersed in sterile BPW & 3 \\
\hline 2 & & Swabs from cutter/knife & 3 \\
\hline 3 & & Meat rinsing water $(25 \mathrm{ml}$ in $25 \mathrm{ml} 2 \mathrm{x}$ BPW) & 3 \\
\hline 4 & & Chicken carcasses (5 carcasses/shop) & 15 \\
\hline 5 & & Ileal contents from five carcasses & 15 \\
\hline 6 & & Cecal contents from five carcasses & 15 \\
\hline
\end{tabular}

$(\mathrm{CAC}=30 / 10 \mu \mathrm{g}), \quad$ and cefpodoxime+clavulanic acid $(\mathrm{CCL}=10 / 05 \mu \mathrm{g})$. Interpretation of the results was carried out as per European Committee on Antimicrobial Susceptibility Testing (EUCAST) [14] and Clinical and Laboratory Standard Institute (CLSI) wherever the EUCAST breakpoints were not available. There are no breakpoints for doxycycline, instead the breakpoints for tetracycline were used. The Salmonella isolates were classified as susceptible or resistant to the antimicrobial agents used.

2.6. Screening of the Salmonella Isolates for ESBL. Salmonella isolates were subjected for ESBL screening, and the results were interpreted as per CLSI [15]. Resistance to at least one of the three antibiotics (cefotaxime $(\leq 27 \mathrm{~mm})$, ceftazidime $(\leq 22 \mathrm{~mm})$, and cefpodoxime $(\leq 17 \mathrm{~mm})$ ) was considered as positive in the screening test for possible ESBL production. Isolates of Salmonella that were considered to be positive for ESBL production by the screening test were subjected to the phenotypic confirmatory test [16] using disks of cefotaxime + clavulanic acid $(\mathrm{CEC}=30 / 10 \mu \mathrm{g})$, ceftazidime + clavulanic acid $(\mathrm{CAC}=30 / 10 \mu \mathrm{g})$, and cefpodoxime + clavulanic acid $(\mathrm{CCL}=10 / 5 \mu \mathrm{g})$. An increase in the zone diameter by $\geq 5 \mathrm{~mm}$ containing cephalosporin with cla- vulanic acid over the disks containing cephalosporin alone for any one of the groups indicated ESBL production.

2.7. Determination of Minimum Inhibitory Concentration (MIC) of Colistin. Standard broth microdilution technique [15] was employed for assessing the MIC of colistin sulphate (CS), using cation-adjusted Mueller-Hinton broth (CAMHB, HiMedia). The test was performed in untreated polystyrene flat bottom 96 well plates. Different concentrations of colistin sulphate ranging from 0.25 to $128 \mathrm{mg} / \mathrm{L}$ were prepared in CAMHB in plates and were inoculated with the isolates, and the plates were incubated at $37^{\circ} \mathrm{C}$ for $18 \mathrm{hrs}$. The MIC end point was determined as the lowest concentration of colistin that completely inhibited visible growth (Figure 1).

Sterility control (SC, CAMHB only), highest antibiotic control (HAC): CAMHB $+128 \mu \mathrm{g} / \mathrm{mL}$ of colistin, and lowest antibiotic control (LAC): CAMHB $+0.25 \mu \mathrm{g} / \mathrm{mL}$ were maintained in duplicates in each plate. Escherichia coli (ATCC ${ }^{\circledR}$ $25922^{\mathrm{TM}}$ ) was used as quality control for each batch of screening. The cut-off value was interpreted as per the EUCAST breakpoint $(2 \mu \mathrm{g} / \mathrm{mL}$ for colistin sulphate), and the OD value of 0.1 at $600 \mathrm{~nm}$ was considered as the cut- 


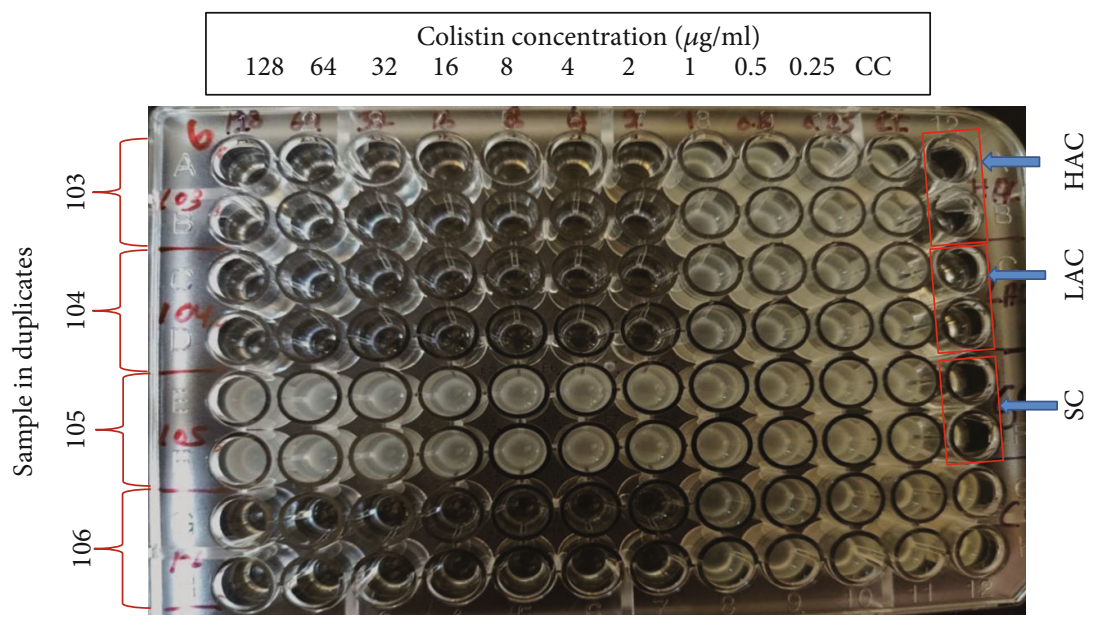

Figure 1: Determination of MIC of colistin sulphate for the Salmonella isolates: Salmonella isolates 103, 104, 105, and 106. CC: culture control; HAC: highest antibiotic control; LAC: lowest antibiotic control; SC: sterility control wells.

off value for conversion into numeric data to determine the resistance or sensitivity of the isolates.

\section{Results}

3.1. Isolation of Salmonella Using Three Different Media and Colony PCR. All the 182 samples collected from hatcheries, $\mathrm{CBF}$, and RMS after selective enrichment were plated onto three different selective media XLD, XLT4, and BGA, and samples that revealed black centred colonies with red coloration of the media on XLD and XLT4 and pink or pinkish white colonies on BGA were considered to be presumptive for Salmonella. Of the 182 samples tested, 143 (78.57\%), 115 (63.18\%), and 106 (58.24\%) samples were showing suspicious colonies on XLD, XLT4, and BGA, respectively $(P<0.002)$. In the present study, colonies that appeared irregularly shaped, translucent, and black centred with red coloration of the media (i.e., nonlactose fermentative) in XLD and XLT4 were confirmed to be Salmonella by both biochemical tests and PCR (Figures 2 and 3), whereas colonies that appeared regular, opaque, and black centred without red coloration in XLD and XLT4 (Figures 4 and 5) were negative for Salmonella by both biochemical tests and PCR. Similarly, in BGA, typical pink or pinkish white colonies with red coloration of the media were confirmed as Salmonella by biochemical tests and PCR (Figure 6), while yellow color colonies without red coloration of the media on BGA were confirmed as negative for Salmonella by biochemical tests and PCR (Figure 7).

All the presumptive or suspected colonies were subjected to biochemical test and PCR targeting the hilA gene, and it was observed that only 29 (15.93\%) each from XLD and BGA and 28 (15.38\%) from XLT4 agar were positive and confirmed as Salmonella (Figure 8). A total of 106 Salmonella isolates were obtained in this study and were used for further characterization.

In the present study, it was found that enrichment of all the 182 samples in TTB followed by DNA extraction and PCR targeting the hilA gene, 52 samples (28.57\%) were found positive for Salmonella as compared to $29(15.93 \%)$

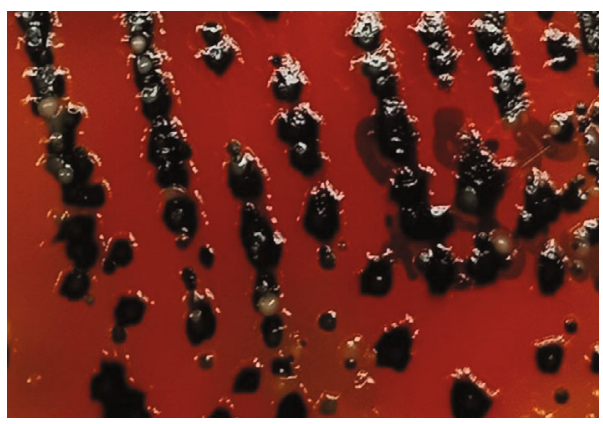

FIGURE 2: Black centred irregular translucent colonies with red coloration of the media in XLD.

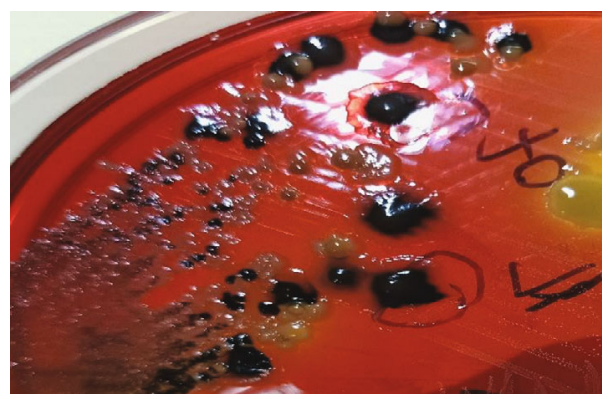

FIgURE 3: Black centred irregular translucent colonies with red coloration of the media in XLT4.

samples each in XLD and BGA and 28 (15.38\%) samples in XLT4 $(P<0.001)$, indicating that enrichment followed by direct DNA extraction and PCR was more sensitive compared to enrichment followed by selective plating and colony PCR (Table 2 and Figure 9).

3.2. Prevalence of Salmonella. In the present study, the overall prevalence of Salmonella in broiler supply chain was $25.82 \%(47 / 182)$. A significantly higher $(P<0.001)$ prevalence was observed in RMS (25/54; 46.29\% (25/54)), followed by CBF (19/99; 19.19\%) and hatcheries (3/29; $10.34 \%$ ). In the hatcheries, samples from incubator air 


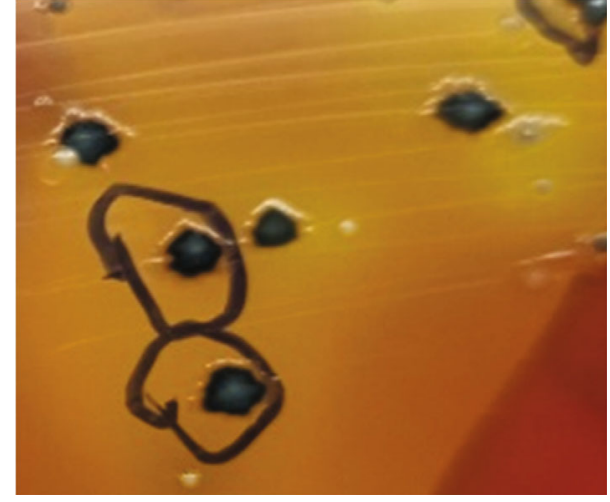

FIGURE 4: Black centred opaque colonies without red coloration of the media in XLD.

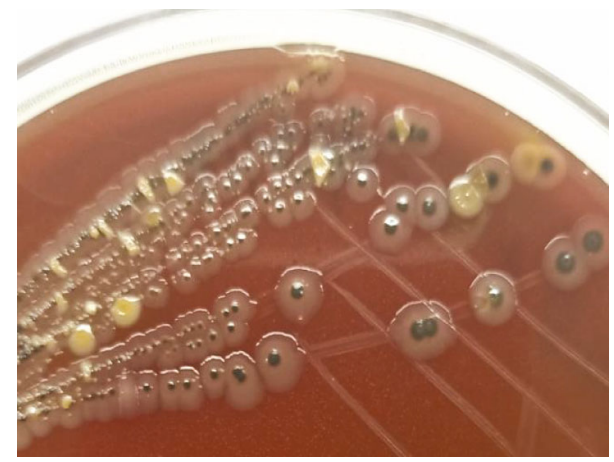

FIGURE 5: Black centred opaque colonies without red coloration of the media in XLT4.

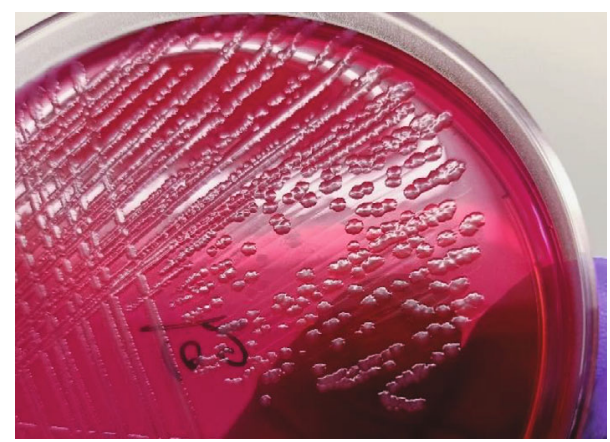

FIGURE 6: Typical pink or pinkish white Salmonella colonies with red coloration of the media in BGA.

tunnels, egg tray of hatchers, and yolk sac from dead chicks were positive for Salmonella (Table 3). With respect to CBF, the prevalence of Salmonella was highest from samples collected from day $0(10 / 33 ; 30.30 \%)$, followed by days $35-42$ $(6 / 33 ; 18.18 \%)$ and days $18-20(3 / 33 ; 9.09 \%)$. In addition, in $\mathrm{CBF}$, the prevalence in samples collected from internal environment of the farms was $40 \%(6 / 15)$ as compared to samples collected from external environment $(3 / 9 ; 33.33 \%)$, followed by faecal swabs (5/15: $33.33 \%)$, water sample from nipples/drinkers, and feed sample from different feeders $(2 / 15 ; 13.33 \%)$ and feed bags $(1 / 15 ; 6.66 \%)$ (Table 4$)$. How-

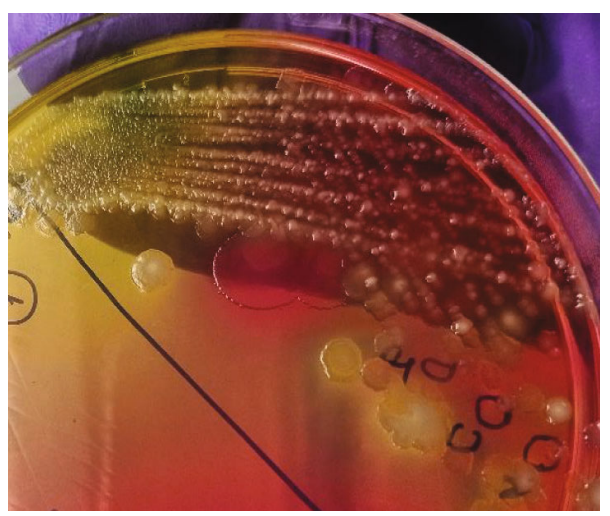

FIGURE 7: Yellow color colonies without red coloration of the media in BGA.

ever, none of the samples collected from water tank were positive. In RMS, Salmonella was recovered from ileal and cecal contents, chicken carcasses, meat rinsing water, and knife swabs. On the other hand, none of the swabs from surface of cutting/chopping board sample were positive (Table 5).

3.3. Detection of Salmonella enterica. Among 106 Salmonella isolates, 69 (65.09\%) were confirmed as Salmonella enterica by species-specific PCR targeting iroB gene. The prevalence of Salmonella enterica was found to be higher in isolates from RMS $(27 / 36$; 75\%) followed by hatcheries (8/12; 66.66\%) and CBF samples (34/58; 58.62\%) (Table 6 and Figures 10 and Figure 11).

3.4. Antimicrobial Susceptibility Pattern. Antimicrobial susceptibility testing of Salmonella isolates from hatcheries $(n=12)$ revealed that all isolates were resistant to cefpodoxime followed by ciprofloxacin and doxycycline $(58.33 \%)$ and $8.33 \%$ to both gentamycin and cefotaxime, whereas none of the isolates were found resistant to amikacin, neomycin, enrofloxacin, trimethoprim-sulfamethoxazole, chloramphenicol, ampicillin and amoxicillin + clavulanic acid, ceftazidime, and colistin sulphate. Among the CBF isolates $(n=58)$, highest resistance was observed against doxycycline $(100 \%)$ and least to chloramphenicol (3.45\%) (Table 7).

Comparison of antimicrobial susceptibility pattern of $\mathrm{CBF}$ isolates obtained during crop cycles from day 0 to days 35-42 revealed highest resistance to doxycycline and least to chloramphenicol, whereas on days 18-20,100\% resistance was observed for doxycycline, but all the isolates were sensitive to chloramphenicol and trimethoprim-sulfamethoxazole (Table 8). It was evident that through the entire production cycle all the isolates were sensitive to chloramphenicol and were resistant to doxycycline.

In RMS, also highest resistance was recorded against doxycycline $(97.22 \%)$, and least resistance was found to cefotaxime + clavulanic acid (5.56\%). However, isolates were found to be more sensitive to chloramphenicol, colistin sulphate, cefotaxime, ceftazidime, amikacin, amoxicillin + clavulanic acid, ampicillin, and trimethoprimsulfamethoxazole (Table 7). 


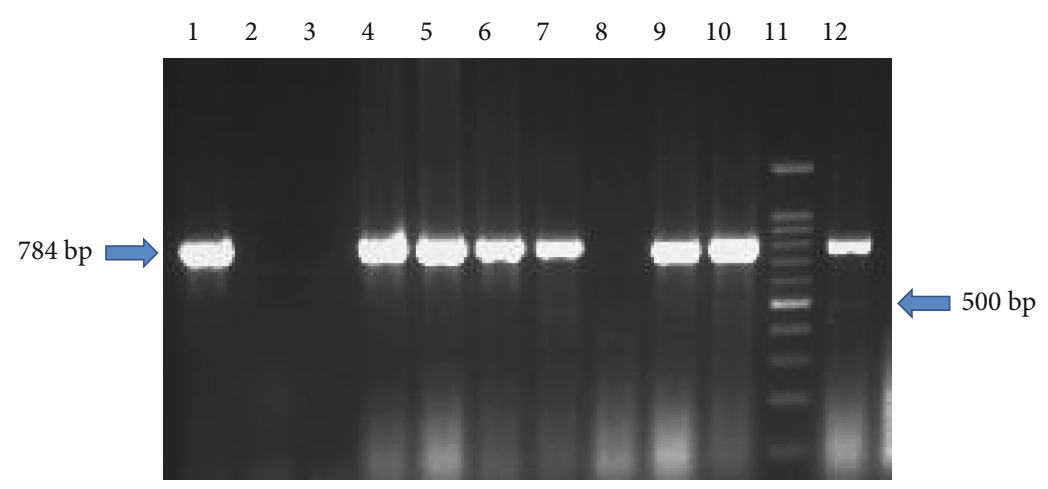

Figure 8: Agarose gel electrophoresis of colony PCR hilA gene amplicon. Lane 1: positive control (Salmonella Typhimurium ATCC 14028); lane 2: negative control (Escherichia coli ATCC ${ }^{\circledR} 25922^{\mathrm{TM}}$ ); lane 3: no template control (NTC); lanes 4, 5, 6, 7, 9, 10, and 12: samples positive for Salmonella spp.; lane 8: sample negative for Salmonella spp.; lane 11: 100 bp DNA ladder.

TABLE 2: Comparison of conventional culturing method and PCR for detection of Salmonella in different poultry samples.

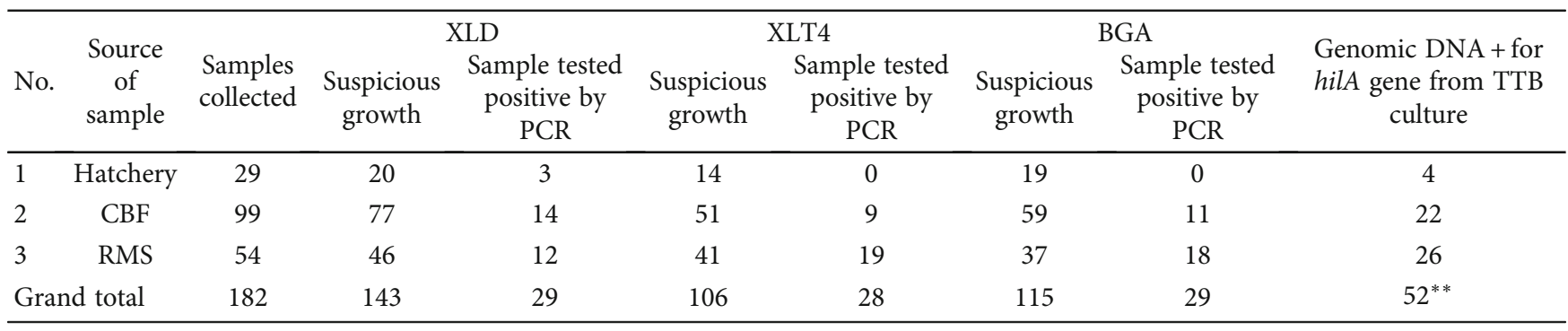

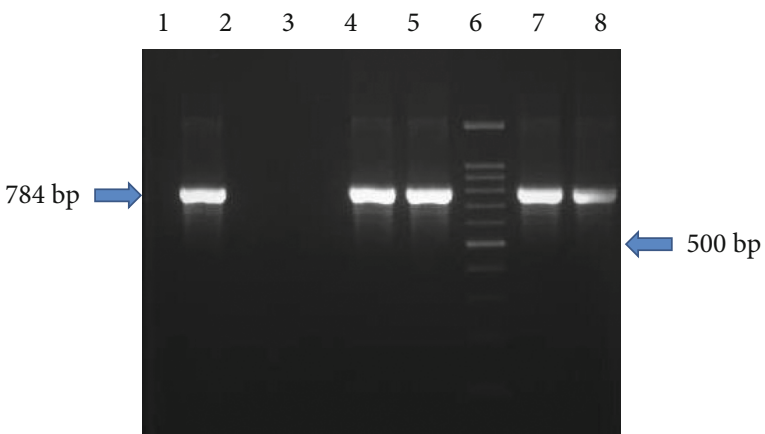

FIGURE 9: Agarose gel electrophoresis of hilA gene amplicon from TTB culture. Lane 1: positive control (Salmonella Typhimurium ATCC 14028); lane 2: negative control (Escherichia coli ATCC ${ }^{\circledR}$ $\left.25922^{\mathrm{TM}}\right)$; lane3: NTC; lanes 4, 5, 7, and 8: samples positive for Salmonella spp.; lane 6: 100 bp DNA ladder.

3.5. ESBL Producers. In the present study, it was observed that $18 / 106(16.98 \%)$ of the isolates were ESBL producers. The prevalence was $27.7 \%(10 / 36)$ in RMS and $13.59 \%$ $(8 / 58)$ in $\mathrm{CBF}$, and none of the isolates from hatcheries were ESBL producers (Table 7). With respect to the Salmonella isolated from CBF, the highest number of ESBL producing isolates was detected on day zero $(4 / 28 ; 14.29 \%)$ followed by days $35-42(3 / 20 ; 15 \%)$ and lowest being recorded on days $18-20(1 / 10 ; 10 \%)$ (Table 8$)$.

3.6. Colistin Resistance. Initially, all the 106 isolates were subjected to disc diffusion assay, and 47 isolates which were found to be resistant were subjected to MIC for colistin. It was observed that in the complete broiler production chain, $40.42 \%$ of the isolates were resistant (MIC of $>2 \mu \mathrm{g} / \mathrm{mL}$ ). No significant difference was observed in colistin resistance with respect to isolates obtained from $\mathrm{CBF}$ and RMS, and none of the isolates from hatcheries were resistant to colistin sulphate (Figure 1 and Table 7).

3.7. Multidrug Resistance (MDR). In the present study, it was observed that $76.41 \%$ of Salmonella isolates were MDR, as defined by resistance to at least one agent in three or more categories of antibiotics [17]. The prevalence of MDR was highest in RMS (91.66\%) followed by CBF (82.75\%), and none of the hatcheries' isolates exhibited MDR.

3.8. AMR Pattern in Complete Supply Chain. In the present study, $100 \%$ of the isolates were resistant to at least one antibiotic. Irrespective of the sample source, highest resistance was observed to doxycycline (94.34\%) followed by cefpodoxime $(84.91 \%)$, ciprofloxacin $(72.64 \%)$, gentamicin (65.09\%), enrofloxacin (61.32\%), colistin sulphate (40.42\%), amikacin (34.91\%), ampicillin (33.96\%), neomycin (33.02), cefotaxime (30.19\%), ceftazidime (29.25\%), trimethoprim-sulfamethoxazole (23.58\%), amoxicillin + clavulanic acid (21.70\%), and chloramphenicol (12.26\%) (Table 7).

\section{Discussion}

Salmonella is one of the leading foodborne pathogens in humans. Prevalence of Salmonella in food animals and 
TABle 3: Detection of Salmonella in hatcheries' samples.

\begin{tabular}{lccc}
\hline No. & Types of samples collected & Total no. of samples & Salmonella positive samples \\
\hline 1 & Swabs from egg setting room & 3 & 0 \\
2 & Swabs from incubator/setter & 3 & 0 \\
3 & Swabs from air tunnels and fans of incubators/setter & 3 & 1 \\
4 & Swabs from hatchers & 3 & 0 \\
5 & Swabs from hatcher egg tray & 3 & 0 \\
6 & Meconium swabs & 3 & 1 \\
7 & Yolk sac swab of dead chicks & 3 & 0 \\
8 & Hand swabs from hatchery workers & 5 & 0 \\
9 & Boot socks from hatchery floor & 3 & $3 / 29(10.34 \%)$ \\
Total & & 29 & \\
\hline
\end{tabular}

TABLe 4: Detection of Salmonella in CBF samples.

\begin{tabular}{|c|c|c|c|c|}
\hline No. & Type of samples collected & Sampling time points & Total no. of samples & Salmonella positive samples \\
\hline 1 & Boot socks from internal environment & & 15 & 6 \\
\hline 2 & Faecal swabs & & 15 & 5 \\
\hline 3 & Boot socks from farm external environment & & 9 & 3 \\
\hline 4 & Feed sample from different feeders & Day 1 , days $18-20$, and days $35-42$ & 15 & 2 \\
\hline 5 & Water sample from nipples/drinkers & & 15 & 2 \\
\hline 6 & Feed sample from feed bags & & 15 & 1 \\
\hline 7 & Water sample from water tank & & 15 & 0 \\
\hline Total & & & 99 & 19/99 (19.19\%) \\
\hline
\end{tabular}

TABLE 5: Detection of Salmonella in samples collected from RMS.

\begin{tabular}{lcc}
\hline Type of samples & $\begin{array}{c}\text { No. of } \\
\text { samples }\end{array}$ & $\begin{array}{c}\text { Salmonella positive } \\
\text { samples }\end{array}$ \\
\hline Ileal contents & 15 & 9 \\
Cecal contents & 15 & 9 \\
Chicken carcasses & 15 & 4 \\
Meat rinsing water & 3 & 2 \\
Swabs from cutter/knife & 3 & 1 \\
$\begin{array}{l}\text { Swabs from of cutting/ } \\
\text { chopping board }\end{array}$ & 3 & 0 \\
Total number & 54 & $25 / 54(46.29 \%)$ \\
\hline
\end{tabular}

TABLE 6: Detection of Salmonella enterica in poultry supply chain.

\begin{tabular}{lcccc}
\hline No. & $\begin{array}{c}\text { Source of } \\
\text { sample }\end{array}$ & $\begin{array}{c}\text { No. of } \\
\text { samples } \\
\text { collected }\end{array}$ & $\begin{array}{c}\text { No. of } \\
\text { Salmonella } \\
\text { isolates }\end{array}$ & $\begin{array}{c}\text { No. of Salmonella } \\
\text { enterica isolates }\end{array}$ \\
\hline 1 & Hatcheries & 29 & 12 & 8 \\
2 & CBF & 99 & 58 & 34 \\
3 & RMS & 54 & 36 & 27 \\
Total & & 182 & 106 & $69 / 106(65.06 \%)$ \\
\hline
\end{tabular}

increasing AMR poses a continuous threat to one health approach.

Salmonella also causes major economic losses to poultry industry. Poultry producers face many direct losses from Salmonella infections in their flocks. Infections acquired ver- tically from parents or horizontally in the hatchery can cause growth retardation or even mortality in young chicks. Preventing the transmission of Salmonella to progeny or to humans can be expensive for poultry farmers. In the present study, the prevalence of Salmonella was investigated in complete poultry supply chain from hatcheries to retail meat shops.

In the present study, three selective agar media, viz., XLD, BGA, and XLT4, were compared for isolation and recovery of Salmonella from various poultry samples, and results revealed that they did not show any significant differences. These findings are in agreement with the earlier findings [18]. However, few researchers $[19,20]$ have reported that XLT4 was a better medium for isolation of Salmonella with nearly $100 \%$ success. On the other hand, the colonies not confirmed as Salmonella was observed for XLD $(143 / 182)$ followed by BGA $(115 / 182)$ and XLT4 $(106 / 182)$. This may be because of the presence of Tergtitol 4 detergent in XLT4, and this could have inhibited the growth of Proteus spp. that produce colonies similar to Salmonella in XLD. The comparison of enrichment culturebased PCR assay had detected very higher number of positive samples compared to culture methods. It was evident from this study that enrichment followed by direct DNA extraction from enriched culture and PCR was a sensitive method which eliminates the processing of negative samples. It is also clear that enrichment in TTB followed by selective plating and colony PCR employing both standard culture method in combination with molecular methods such as 


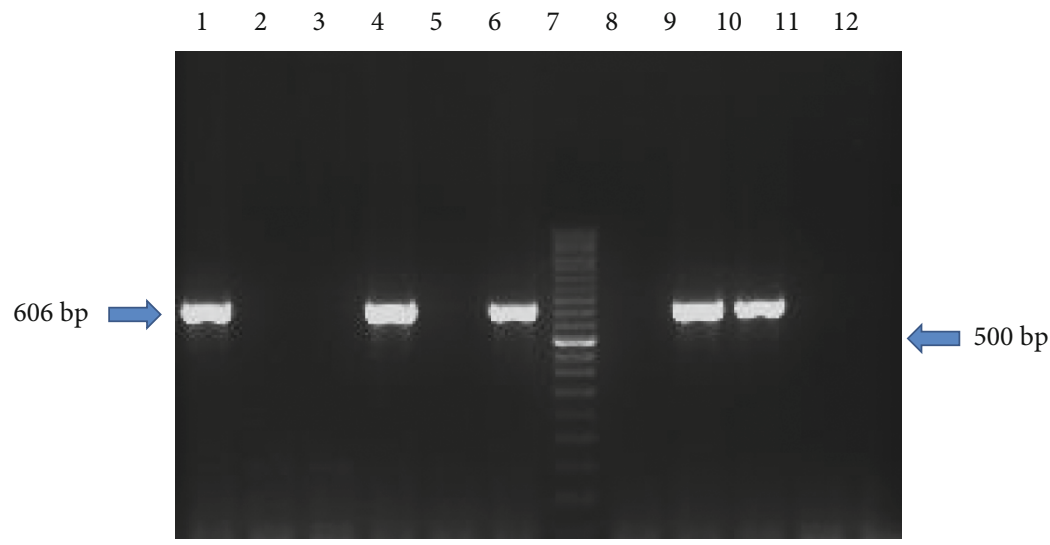

Figure 10: Agarose gel electrophoresis of iroB gene amplicon for Salmonella enterica. Lane 1: positive control (Salmonella Typhimurium ATCC 14028); lane 2: negative control (Escherichia coli ATCC $^{\circledR} 25922^{\mathrm{TM}}$ ); lane 3: NTC; lanes 4, 6, 9, and 10: samples positive for Salmonella spp.; lanes 5,8, 11, and 12: samples negative for Salmonella spp.; lane 7: 50 bp DNA ladder.

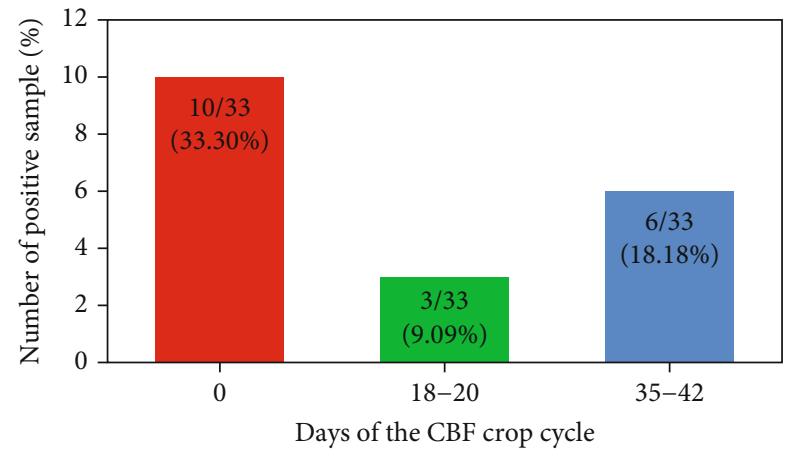

Figure 11: Detection of Salmonella in CBF at different points of crop cycle.

colony PCR for Salmonella detection could be simple, rapid, and effective. This finding was in agreement with earlier studies [21-23].

The overall prevalence of Salmonella in the present study was $25.82 \%$. These findings are in line with other researchers who have reported higher prevalence of Salmonellae in chilled chicken meat samples (51\%) [24], CBF (32.5\%), backyard chicken (21.4\%) [25], CBF supply chain (14.52\%) [26], poultry meat (8.18\%) [27], and egg contents $(0.5 \%)[28]$.

This study revealed varied prevalence of Salmonella in different stages of the poultry supply chain including hatcheries (10.34\%), CBF (19.19\%), and RMS (46.29\%). This indicated a gradual increase in the presence of Salmonella in the poultry supply chain. Statistical analysis revealed significantly higher risk of Salmonella contamination in retail meat shops. Similar findings have been reported earlier [26], where it was shown that majority of the Salmonella Enteritidis strains spread along the broiler chicken supply chain. Presence of Salmonella in hatcheries is a major point of risk for the complete supply chain such as CBF and even retail meat shops as it causes huge mortality in young chicks and its control becomes very difficult in the farm. In our study, the detection of Salmonella in hatcheries (10.34\%) was higher as compared to the previous studies with observation of $2.9 \%$ in eggs, $2.4 \%$ in egg shell, and $0.5 \%$ in egg contents [28]. In the present investigation, it was observed that incubator air tunnel had higher presence of Salmonella. This is of significance as the entire incubator air is supplied through it, and it could be a source of infection for all the eggs in the incubator. Besides, the presence of Salmonella in hatcheries indicated that the hatcheries and its environment have not properly been cleaned and disinfected. Hence, maintenance of cleanliness and hygienic practices during the incubation and hatching process is very important and crucial for control of Salmonella infections in chicks and to prevent further transmission of infection to the CBFs.

Similarly, high presence of Salmonella (19.19\%) was observed in CBF especially at day zero, clearly indicating lack of biosecurity and hygienic practices in CBF. The findings are in concurrence with earlier studies [29-31], where $4.35 \%$ to $20 \%$ prevalence of Salmonella was reported in $\mathrm{CBF}$, respectively. In this study, boot sock samples were collected from the farm environment before arrival of the chicks in the farm, and it was found that such samples were positive for Salmonella, indicating that some of the farms were contaminated even before placement of the day-old chicks.

In the present study, the overall prevalence of Salmonella in RMS was $46.29 \%$, which is in agreement with the earlier findings of 51\% prevalence in India [24] but higher than those reported in chicken meat samples in Turkey (10.64\%) [32], broiler supply chain in Qingdao City, China (14.98\%) [26], chicken meat from wet markets in Malaysia (20.8\%) [33], broiler supply chain in Korea (16.06\%) [34], or from different chicken samples in slaughter houses in China (30.14\%) [35]. The higher prevalence of Salmonella in RMS in our study may be attributed to the fact that majority of the retail meat shops are open type shops, selling meat to the consumers directly, after slaughter of live birds. Moreover, all the operations of bleeding, skinning, and cutting are carried out in small premises without any demarcation of different slaughter and dressing operations. The hygienic practices and cleanliness are at very minimum level in these shops, and on other hand, they receive potentially infected live birds on daily basis from different broiler 
TABLE 7: Antimicrobial resistance of Salmonella isolates to various antibiotics.

\begin{tabular}{|c|c|c|c|c|c|c|}
\hline \multirow[b]{2}{*}{ Class of antibiotic } & \multirow[b]{2}{*}{ Name of antibiotics } & \multicolumn{4}{|c|}{ Percentage of AMR of Salmonella isolates } & \multirow[b]{2}{*}{$P$ value } \\
\hline & & $\begin{array}{l}\text { Hatcheries } \\
n=12(\%)\end{array}$ & $\begin{array}{c}\text { CBF } \\
n=58(\%)\end{array}$ & $\begin{array}{c}\text { RMS } \\
n=36(\%)\end{array}$ & $\begin{array}{c}\text { Total } \\
n=106(\%)\end{array}$ & \\
\hline \multirow{3}{*}{ Aminoglycosides } & GEN & $1 / 12(8.33)$ & $48 / 58(82.76)$ & $20 / 36(55.56)$ & $69 / 106(65.09)$ & $<0.01$ \\
\hline & $\mathrm{AK}$ & $0 / 12(0.00)$ & $23 / 58(39.66)$ & $14 / 36(38.89)$ & $37 / 106(34.91)$ & $<0.02$ \\
\hline & $\mathrm{N}$ & $0 / 12(0.00)$ & $18 / 58(31.03)$ & $17 / 36(47.22)$ & $35 / 106(33.02)$ & $<0.01$ \\
\hline \multirow{2}{*}{ Fluoroquinolones } & CIP & $7 / 12(58.33)$ & $41 / 58(70.69)$ & $29 / 36(80.56)$ & $77 / 106(72.64)$ & $<0.20$ \\
\hline & EX & $0 / 12(0.00)$ & $38 / 58(65.52)$ & $27 / 36(75.00)$ & $65 / 106(61.32)$ & $<0.01$ \\
\hline Tetracycline & DO & $7 / 12(58.33)$ & $58 / 58(100.00)$ & $35 / 36(97.22)$ & $100 / 106(94.34)$ & $<0.01$ \\
\hline Folate pathway inhibitors & COT & $0 / 12(0.00)$ & $9 / 58(15.52)$ & $16 / 36(44.44)$ & $25 / 106(23.58)$ & $<0.01$ \\
\hline Phenicols & $\mathrm{C}$ & $0 / 12(0.00)$ & $2 / 58(3.45)$ & $11 / 36(30.56)$ & $13 / 106(12.26)$ & $<0.01$ \\
\hline \multirow{2}{*}{ Penicillin/b-lactamase inhibitors } & AMP & $0 / 12(0.00)$ & $21 / 58(36.21)$ & $15 / 36(41.67)$ & $36 / 106(33.96)$ & $<0.02$ \\
\hline & $\mathrm{AMC}$ & $0 / 12(0.00)$ & $9 / 58(15.52)$ & $14 / 36(38.89)$ & $23 / 106(21.70)$ & $<0.01$ \\
\hline Polymyxins & CS & $0 / 12(0.00)$ & $9 / 28(32.14)$ & $6 / 19(31.58)$ & $19 / 47(40.42)$ & $<0.01$ \\
\hline \multirow{6}{*}{$\begin{array}{l}\text { Extended-spectrum cephalosporins; } \\
\text { 3rd and } 4 \text { th generation cephalosporins/ } \\
\text { b-lactamase inhibitors }\end{array}$} & CTX & $1 / 12(8.33)$ & $18 / 58(31.03)$ & $13 / 36(36.11)$ & $32 / 106(30.19)$ & $<0.05$ \\
\hline & CAZ & $0 / 12(0.00)$ & $18 / 58(31.03)$ & $13 / 36(36.11)$ & $31 / 106(29.25)$ & $<0.05$ \\
\hline & $\mathrm{CPD}$ & 100.00 & $45 / 58(77.59)$ & $33 / 36(91.67)$ & $90 / 106(84.91)$ & $<0.01$ \\
\hline & CEC & 0.00 & $3 / 58(5.17)$ & $2 / 36(5.56)$ & $5 / 106(4.72)$ & $<0.70$ \\
\hline & $\mathrm{CAC}$ & 0.00 & $3 / 58(5.17)$ & $6 / 36(16.67)$ & 9/106 (8.49) & $<0.08$ \\
\hline & CCL & 0.00 & $2 / 58(3.45)$ & $4 / 36(11.11)$ & $6 / 106(5.66)$ & $<0.19$ \\
\hline Average ESBLS & & 0.00 & 13.79 & 27.78 & 16.98 & \\
\hline
\end{tabular}

TABLE 8: Antimicrobial resistance of Salmonella isolates to various antibiotics in different points of CBF crop cycle.

\begin{tabular}{|c|c|c|c|c|c|}
\hline \multirow[b]{2}{*}{ Class of antibiotic } & \multirow[b]{2}{*}{ Name of antibiotics } & \multicolumn{3}{|c|}{ Percentage of AMR of Salmonella isolates } & \multirow[b]{2}{*}{$P$ value } \\
\hline & & $\begin{array}{c}\text { Day } 0 \\
n=28(\%)\end{array}$ & $\begin{array}{c}\text { Days } 18-20 \\
n=10(\%)\end{array}$ & $\begin{array}{c}\text { Days } 35-42 \\
n=20(\%)\end{array}$ & \\
\hline \multirow{3}{*}{ Aminoglycosides } & GEN & $23 / 28(82.14)$ & $10 / 10(100.00)$ & $15 / 20(75.00)$ & $<0.02$ \\
\hline & $\mathrm{AK}$ & $8 / 28(28.57)$ & $7(70.00)$ & $8 / 20(40.00)$ & $<0.07$ \\
\hline & $\mathrm{N}$ & $2 / 28(7.14)$ & $7(70.00)$ & $3 / 20(15.00)$ & $<0.01$ \\
\hline \multirow{2}{*}{ Fluoroquinolones } & CIP & $19 / 28(67.86)$ & $10 / 10(100.00)$ & $12 / 20(60.00)$ & $<0.06$ \\
\hline & EX & $18 / 28(64.85)$ & $10 / 10(100.00)$ & $10 / 20(50.00)$ & $<0.02$ \\
\hline Tetracycline & DO & $28 / 28(100.00)$ & $10 / 10(100.00)$ & $20 / 20(100.00)$ & $<0.05$ \\
\hline Folate pathway inhibitors & COT & $7 / 28(25.00)$ & $0 / 10(0.00)$ & $10 / 20(10.00)$ & $<0.01$ \\
\hline Phenicols & $\mathrm{C}$ & $1 / 28(3.57)$ & $0 / 10(0.00)$ & $1 / 20(5.00)$ & $<0.70$ \\
\hline \multirow{2}{*}{ Penicillin/b-lactamase inhibitors } & AMP & $8 / 28(28.57)$ & $4 / 10(40.00)$ & $9 / 20(45.00)$ & $<0.01$ \\
\hline & AMC & $3 / 28(10.71)$ & $2 / 10(20.00)$ & $4 / 20(20.00)$ & $<0.62$ \\
\hline Polymyxins & CS & $6 / 14(42.86)$ & $1 / 6(16.67)$ & $2 / 8(25.00)$ & $<0.18$ \\
\hline \multirow{6}{*}{$\begin{array}{l}\text { Extended-spectrum cephalosporins; } \\
\text { 3rd and 4th generation cephalosporins/ } \\
\text { b-lactamase inhibitors }\end{array}$} & CTX & $2 / 28(7.14)$ & $7 / 10(70.00)$ & $9 / 20(45.00)$ & $<0.05$ \\
\hline & CAZ & $2 / 28(7.14)$ & $7 / 10(70.00)$ & $9 / 20(45.00)$ & $<0.01$ \\
\hline & $\mathrm{CPD}$ & $23 / 28(82.14)$ & $9 / 10(90.00)$ & $13 / 20(65.00)$ & $<0.34$ \\
\hline & CEC & $2 / 28(7.14)$ & $1 / 10(10.00)$ & $0 / 20(0.00)$ & $<0.40$ \\
\hline & CAC & $1 / 28(3.57)$ & $0 / 10(0.00)$ & $3 / 20(15.00)$ & $<0.15$ \\
\hline & CCL & $4 / 28(7.14)$ & $0 / 10(0.00)$ & $0 / 20(0.00)$ & $<0.10$ \\
\hline Average ESBLS & & 14.29 & 10.00 & 15.00 & \\
\hline
\end{tabular}

suppliers. In the present study, prevalence of Salmonella in ileal and cecal contents, carcass rinse, meat rinsing water, and knife swabs had indicated that Salmonella is distributed among the various samples of the retail meat shops and its environment.
In this study, very high prevalence $(65.09 \%)$ of Salmonella enterica was detected among the poultry isolates. Salmonella enterica serotypes are among the most common cause of food poisoning in humans [36]. Salmonella enterica represents the most pathogenic species and includes $>2600$ 
serovars. Salmonella can be transmitted to humans along the farm-to-fork continuum [37]. We found that the prevalence of Salmonella enterica was higher in isolates from RMS samples, followed by hatcheries and CBF. Similar finding was reported in China [38], Egypt [39], and Haryana, India [40].

The results of antimicrobial susceptibility testing revealed that $100 \%$ of the isolates were resistant to at least one of the antibiotics with $76.41 \%$ being MDR. The MDR was highest in RMS followed by CBF and hatcheries. Similar to the findings of our study, high MDR Salmonella (100\%) was reported from retail chicken meat shops in North India (100\%) [30], along the slaughtering line in China (78.6\%) [35] and Egypt (76.7\%) [39], healthy chicken samples in Korea (63.6\%) [41], and poultry isolates in Turkey (46.4\%) [32].

The findings of this study clearly indicate that there was higher AMR to tetracyclines, $\beta$-lactams, fluoroquinolones, aminoglycosides, polymyxin, ESBL inhibitors, folate pathway inhibitors, and less resistance to phenicols. Similar finding has been reported elsewhere for $\beta$-lactam and macrolide antibiotics (52.9-100\%) [25] while lesser resistance to chloramphenicol (3.13\%) and higher resistance to ciprofloxacin and $\beta$-lactams (68.75-100\%), tetracycline $(65.62 \%)$, and colistin sulphate $(46.87 \%)$ were reported in other studies [42]. Previous researchers have reported that there was shift in antibiotics selection used for treatment of Salmonella infections in poultry, from chloramphenicol and ampicillin to trimethoprim-sulfamethoxazole, fluoroquinolones, and extended-spectrum cephalosporins [43, 44]. The unjudicial use of antibiotics may be one of the main reasons for increased resistance to $\beta$-lactams, tetracycline, and fluoroquinolones.

High prevalence of MDR in Gram-negative bacteria has increased the importance of polymyxins, especially polymyxin E (colistin) for the management of Gramnegative infections in many countries. In the present study, surprisingly, a high prevalence of colistin resistance was observed in entire broiler supply chain (40.42\%) although its use is banned in food animals including poultry in India [45] [46]. Similar findings (46.87\%) were reported by earlier researchers in India [43]. But higher resistance against colistin (92.68\%) was recorded in Bangladesh [47] and lesser (20\%) in Serbia [48] and (4.76\%) in Mumbai, India [49]. It is beyond the scope of this study to attribute colistin resistance to a particular reason.

Comparison of different segments of the poultry supply chain revealed higher AMR in retail meat shops followed by $\mathrm{CBF}$ and hatcheries. This may be due to the frequent use of antibiotics in the CBF and horizontal gene transfer in the intestine of poultry chicken [25]. Cages, workers' hand, and vehicles used for transportation of the chicken may also play a role in transmission of resistant bacteria from farm to retail shops.

\section{Conclusion}

The results of the present study indicated that XLT4 and BGA were found to be specific for isolation followed by colony PCR for identification of Salmonella from poultry sam- ples. In addition, enrichment of poultry samples in TTB followed by PCR was found to reduce the preenrichment and isolation protocols. The study also revealed higher prevalence of antimicrobial resistant Salmonella in the entire broiler supply chain, which warrants immediate action in terms of reducing the use of antimicrobials as well as biosecurity measures which would help to decrease the emergence of AMR Salmonella.

\section{Data Availability}

Data was analysed using the GraphPad Prism 5 software and Chi-square test.

\section{Conflicts of Interest}

All authors of this article declare no conflict of interest.

\section{Acknowledgments}

This work was supported by the Indo-UK project (BT/IN/Indo-UK/AMR/05/NH/2018-19), Chicken or egg: Drivers of antimicrobial resistance in poultry in India, by Department of Biotechnology, Ministry of Science and Technology, Government of India to SI and NRH, and conducted in the Department of Veterinary Microbiology, Veterinary College, Hebbal, Bengaluru-560024, India.

\section{References}

[1] D. Shao, Z. Shi, J. Wei, and Z. Ma, "A brief review of foodborne zoonoses in China," Epidemiology and Infection, vol. 139, no. 10, pp. 1497-1504, 2011.

[2] B. R. Jackson, P. M. Griffin, D. Cole, K. A. Walsh, and S. J. Chai, "Outbreak-associatedSalmonella entericaSerotypes and food commodities, United States, 1998-2008," Emerging Infectious Diseases, vol. 19, no. 8, pp. 1239-1244, 2013.

[3] J. L. Smith and P. M. Fratamico, "Factors involved in the emergence and persistence of food-borne diseases," Journal of Food Protection, vol. 58, no. 6, pp. 696-708, 1995.

[4] L. R. Ward, "Salmonella enteritidis epidemic," Science, vol. 287, no. 5459, pp. 1753c-11753, 2000.

[5] S. Y. Youn, O. M. Jeong, B. K. Choi, S. C. Jung, and M. S. Kang, "Comparison of the antimicrobial and sanitizer resistance ofSalmonellaIsolates from chicken slaughter processes in Korea," Journal of Food Science, vol. 82, no. 3, pp. 711-717, 2017.

[6] M. L. F. Márquez, M. J. G. Burgos, R. P. Pulido, A. Gálvez, and R. L. López, "Correlations among resistances to different antimicrobial compounds in Salmonella strains from hen eggshells," Journal of Food Protection, vol. 81, no. 2, pp. 178185,2018

[7] N. T. Nhung, N. Chansiripornchai, and J. J. Carrique-Mas, "Antimicrobial resistance in bacterial poultry pathogens: a review," Frontiers in Veterinary Science, vol. 4, 2017.

[8] J. J. Carrique-Mas and R. H. Davies, "Sampling and bacteriological detection of Salmonella in poultry and poultry premises: a review," Revue scientifique et technique (International Office of Epizootics), vol. 27, no. 3, pp. 665677, 2008. 
[9] R. S. Singer, A. E. Mayer, T. E. Hanson, and R. E. Isaacson, "Do microbial interactions and cultivation media decrease the accuracy of Salmonella surveillance systems and outbreak investigations?," Journal of Food Protection, vol. 72, no. 4, pp. 707-713, 2009.

[10] International Organization for Standardization, Horizontal method for the detection, enumeration and serotyping of Salmonella, 2017.

[11] M. H. Abdelhai, "Comparative study of rapid DNA extraction methods of pathogenic bacteria," American Journal of Bioscience and Bioengineering, vol. 4, no. 1, p. 1, 2016.

[12] S. G. Pathmanathan, N. Cardona-Castro, M. M. Sánchez-Jiménez, M. M. Correa-Ochoa, S. D. Puthucheary, and K. L. Thong, "Simple and rapid detection of Salmonella strains by direct PCR amplification of the hilA gene," Journal of Medical Microbiology, vol. 52, no. 9, pp. 773-776, 2003.

[13] A. J. Bäumler, F. Heffron, and R. Reissbrodt, "Rapid detection of Salmonella enterica with primers specific for iroB," Journal of Clinical Microbiology, vol. 35, no. 5, pp. 1224-1230, 1997.

[14] EUCAST, "European Committee on Antimicrobial Susceptibility Testing Breakpoint tables for interpretation of MICs and zone diameters," 2020, http://www.eucast.org/fileadmin/ src/media/PDFs/EUCAST_files/Breakpoint_tables/v_5.0_ Breakpoint_Table_01.pdf.

[15] CLSI, Performance Standards for Antimicrobial Disk and Dilution Susceptibility Tests for Bacteria Isolated from Animals. CLSI Document VET01 5th Edition. Jun 2018, Clinical \& Laboratory Standards Institute (CLSI), 2018.

[16] D. Rawat and D. Nair, "Extended-spectrum B-lactamases in Gram negative bacteria," Journal of Global Infectious Diseases, vol. 2, no. 3, p. 263, 2010.

[17] A. P. Magiorakos, A. Srinivasan, R. B. Carey et al., "Multidrugresistant, extensively drug-resistant and pandrug-resistant bacteria: an international expert proposal for interim standard definitions for acquired resistance," Clinical Microbiology and Infection, vol. 18, no. 3, pp. 268-281, 2012.

[18] G. Zhang, L. Ma, N. Patel, B. Swaminathan, S. Wedel, and M. P. Doyle, "Isolation of Salmonella Typhimurium from outbreak-associated cake mix," Journal of Food Protection, vol. 70, no. 4, pp. 997-1001, 2007.

[19] R. G. Miller, C. R. Tate, E. T. Mallinson, and J. A. Scherrer, "Xylose-Lysine-Tergitol 4: An Improved Selective Agar Medium for the Isolation of Salmonella," Poultry Science, vol. 70, no. 12, pp. 2429-2432, 1991.

[20] H. Dusch and M. Altwegg, "Evaluation of five new plating media for isolation of Salmonella species," Journal of Clinical Microbiology, vol. 33, no. 4, pp. 802-804, 1995.

[21] I. M. Moussa, M. I, Gassem et al., "Using molecular techniques for rapid detection of Salmonella serovars in frozen chicken and chicken products collected from Riyadh, Saudi Arabia," African Journal of Biotechnology, vol. 9, no. 5, pp. 612-619, 2010.

[22] F. G. Paião, L. G. A. Arisitides, L. S. Murate, G. T. Vilas-Bôas, L. A. Vilas-Boas, and M. Shimokomaki, "Detection of Salmonella spp, Salmonella Enteritidis and Typhimurium in naturally infected broiler chickens by a multiplex PCR-based assay," Brazilian Journal of Microbiology, vol. 44, no. 1, pp. 37-42, 2013.

[23] M. M. Gwida and M. A. M. Al-Ashmawy, "Culture versus PCR for salmonella species identification in some dairy products and dairy handlers with special concern to its zoonotic impor- tance," Veterinary Medicine International, vol. 2014, Article ID 502370, 5 pages, 2014.

[24] R. K. Gautam, A. S. Kakatkar, M. N. Karani, and J. R. Bandekar, "Salmonella in Indian ready-to-cook poultry: antibiotic resistance and molecular characterization," Microbiology Research, vol. 8, no. 1, pp. 15-19, 2017.

[25] M. Bhuvaneswa, S. Shanmughap, and K. Natarajase, "Prevalence of multidrug-resistant (MDR) Salmonella enteritidis in poultry and backyard chicken from Tiruchirappalli, India," Microbiology Journal, vol. 5, no. 2, pp. 28-35, 2015.

[26] M. Cui, M. Xie, Z. Qu et al., "Prevalence and antimicrobial resistance of Salmonella isolated from an integrated broiler chicken supply chain in Qingdao, China," Food Control, vol. 62, pp. 270-276, 2016.

[27] V. Kalaba, B. Golić, Ž. Sladojević, and D. Kalaba, "Incidence ofSalmonellaInfantis in poultry meat and products and the resistance of isolates to antimicrobials," IOP Conference Series: Earth and Environmental Science, vol. 85, no. 1, p. 012082, 2017.

[28] K. Tessema, H. Bedu, M. Ejo, and A. Hiko, "Prevalence and antibiotic resistance of salmonella species isolated from chicken eggs by standard bacteriological method," Journal of Veterinary Science \& Technology, vol. 8, no. 1, pp. 1-5, 2017.

[29] S. Li, Y. Zhou, and Z. Miao, "Prevalence and antibiotic resistance of non-typhoidal Salmonella isolated from raw chicken carcasses of commercial broilers and spent hens in Tai'an, China," Frontiers in Microbiology, vol. 8, pp. 1-6, 2017.

[30] J. Sharma, D. Kumar, S. Hussain et al., "Prevalence, antimicrobial resistance and virulence genes characterization of nontyphoidal Salmonella isolated from retail chicken meat shops in Northern India," Food Control, vol. 102, pp. 104-111, 2019.

[31] S. Shubham, Molecular characterization of non-typhoidal Salmonella serovars isolated from commercial broiler farms and retail chicken meat shops with reference to virulence and antimicrobial resistance, [Ph.D. thesis], G.B. Pant University of Agriculture and Technology, Pantnagar - 263145 (Uttarakhand), 2019.

[32] A. Zafer, G. Di, A. Yibar, H. K. Müştak, and Ö. Şahan, "Extended spectrum beta-lactamase activity and multidrug resistance of Salmonella serovars isolated from chicken carcasses from different regions of Turkey," Ankara Üniversitesi Veteriner Fakültesi Dergisi, vol. 62, no. 2, pp. 119-123, 2015.

[33] T. Y. Thung, N. A. Mahyudin, D. F. Basri et al., "Prevalence and antibiotic resistance of Salmonella Enteritidis and Salmonella Typhimurium in raw chicken meat at retail markets in Malaysia," Poultry Science, vol. 95, no. 8, pp. 1888-1893, 2016.

[34] S. W. Choi, J. S. Ha, B. Y. Kim et al., "Prevalence and characterization of Salmonella species in entire steps of a single integrated broiler supply chain in Korea," Poultry Science, vol. 93, no. 5, pp. 1251-1257, 2014.

[35] Y. Zhu, H. Lai, L. Zou et al., "Antimicrobial resistance and resistance genes in Salmonella strains isolated from broiler chickens along the slaughtering process in China," International Journal of Food Microbiology, vol. 259, pp. 43-51, 2017.

[36] S. J. Olsen, L. C. MacKinnon, J. S. Goulding, N. H. Bean, and L. Slutsker, Surveillance for foodborne-disease outbreaks, United States, 1993-1997, vol. 49 of MMWR. CDC surveillance summaries : Morbidity and mortality weekly report. CDC surveillance summaries, , Centers for Disease Control and Prevention, 2000. 
[37] S. M. Jajere, "A review of Salmonella enterica with particular focus on the pathogenicity and virulence factors, host specificity and antimicrobial resistance including multidrug resistance," Veterinary World, vol. 12, no. 4, pp. 504-521, 2019.

[38] J. Wang, J. Li, F. Liu, Y. Cheng, and J. Su, "Characterization of Salmonella enterica isolates from diseased poultry in northern China between 2014 and 2018," Pathogens, vol. 9, no. 2, p. 95, 2020.

[39] R. Elkenany, M. M. Elsayed, A. I. Zakaria, S. A. E. S. El-Sayed, and M. A. Rizk, "Antimicrobial resistance profiles and virulence genotyping of Salmonella enterica serovars recovered from broiler chickens and chicken carcasses in Egypt," BMC Veterinary Research, vol. 15, no. 1, pp. 1-9, 2019.

[40] D. Arora, S. Kumar, N. Jindal, G. Narang, P. K. Kapoor, and N. K. Mahajan, "Prevalence and epidemiology of Salmonella enterica serovar Gallinarum from poultry in some parts of Haryana, India," Veterinary World, vol. 8, no. 11, pp. 13001304, 2015.

[41] H. K. Dessie, D. H. Bae, and Y. J. Lee, "Characterization of integrons and their cassettes in Escherichia coli and Salmonella isolates from poultry in Korea," Poultry Science, vol. 92, no. 11, pp. 3036-3043, 2013.

[42] M. Rahmani, S. M. Peighambari, C. A. Svendsen, L. M. Cavaco, Y. Agersø, and R. S. Hendriksen, "Molecular clonality and antimicrobial resistance in Salmonella entericaserovars Enteritidis and Infantis from broilers in three Northern regions of Iran," BMC Veterinary Research, vol. 9, no. 1, 2013.

[43] I. A. Mir, S. K. Kashyap, and S. Maherchandani, "Isolation, serotype diversity and antibiogram of Salmonella enterica isolated from different species of poultry in India," Asian Pacific Journal of Tropical Biomedicine, vol. 5, no. 7, pp. 561-567, 2015.

[44] S. Malik, P. Roy, and D. Rawat, "A case of extended spectrum beta-lactamase producing salmonella enterica serotype paratyphi A from India," Indian Journal of Pathology \& Microbiology, vol. 58, no. 1, pp. 113-114, 2015.

[45] S. Venkatesh, Minutes of the 81stmeeting of drugs technical advisory board held on 29th November, 2018 at DGHS, Nirman Bhawan, New Delhi2018, https://cdsco.gov.in/opencms/ resources/UploadCDSCOWeb/2018/UploadCommitteeFiles/ dtab29nov18.pdf.

[46] The Union health ministry, Government ban on colistin for use in poultry industry, New Delhi, India, 2019, https://www .hindustantimes.com/india-news/centre-bans-antibioticdrug-colistin-for-use-in-poultry-industry/storyxzX7oxDAGeeQVP2WsqnTwL.html.

[47] M. B. Uddin, S. M. B. Hossain, M. Hasan et al., "Multidrug antimicrobial resistance and molecular detection of MCR-1 gene in salmonella species isolated from chicken," Animals, vol. 11, no. 1, pp. 206-219, 2021.

[48] M. Manic, "Resistance testing of Salmonella Spp. bacteria isolated from samples derived from poultry on antimicrobial drugs," Journal of Dairy, Veterinary and Animal Research, vol. 3, no. 2, pp. 67-71, 2016.

[49] R. N. Waghamare, A. M. Paturkar, V. M. Vaidya et al., "Phenotypic and genotypic drug resistance profile of Salmonella serovars isolated from poultry farm and processing units located in and around Mumbai city, India," Veterinary World, vol. 11, no. 12, pp. 1682-1688, 2018. 